\title{
A lingua na economia da luz como espaço de reflexão sobre o que somos
} The language in the economy of "Estação da Luz" as a space to think of wat we are

\author{
Lucília Maria Souza Romão
}

Universidade de São Paulo, campus de Ribeirão Preto, SP, Brasil

Amanda Eloina Scherer

Universidade Federal de Santa Maria, Santa Maria, RS, Brasil

\begin{abstract}
Resumo: Nosso objetivo, para o presente artigo, é propor algumas questões que envolvam a política de língua via sua monumentalização e patrimonialização, tomando como objeto o Museu da Língua Portuguesa. Tais questões ultrapassam o meramente linguístico e o discursivo para pensarmos sobre as políticas públicas de inclusão/exclusão em um espaço visceral como é caso da Estação da Luz. Lugar de sujeito, espaço e tempo diferenciados, lugar de conflito de toda a espécie e de toda a ordem. Nossa questão principal diz respeito ao lugar da língua e sua constituição nas políticas urbanas de recuperação arquitetônica na/pela circulação de bens e de pessoas.
\end{abstract}

Palavras-chave: Língua. Museu. Conflito. Lugar de sujeito. Constituição.

Abstract: Our goal in this article is to propose some issues involving language policy via its monumentalization and patrimonialization by taking as object the Museum of the Portuguese Language. Such issues go beyond the merely linguistic and discursive levels to think about public policies of inclusion /exclusion in a visceral space as is the case of "Estação da Luz", a place of different subjects, space and time, a place of conflicts of all kinds and of all orders. Our main question concerns the place of the language and its constitution in urban policies of architecture recovery in/by the circulation of goods and people.

Keywords: Language. Museum. Conflict. Place of subject. Constitution. 


\section{A estação...}

Centro econômico visceral do desenvolvimento ferroviário no estado e no país, a Estação da Luz concentrou tráfegos de mercadorias, de gente e de capitais. Abriu as veias comerciais e possibilitou a circulação de cifras e sinais. $O$ café dos anos 20 enredou o entorno da produção e da arquitetura e abraçou a cidade, permitindo a acumulação de sacarias e de inter-

Lucília M. S. câmbios. Ainda hoje, a Estação da Luz amarra uma série de linhas ferro e Romão metroviárias que continuam a fazer circular trabalhadores de aqui e de lá, de outras cidades dentro da capital. Do ponto de vista institucional, Amanda E. trata-se de um local estratégico para transporte público com recorrente Scherer atenção dos olhos, e por que não da língua, das governanças municipais e estaduais. É local de passagem febril, de apressadas conexões, de che340 gadas e de partidas, de vozes que se deslocam e deslizam entre efeitos de escadas, portas e túneis. Às vezes, ao som de um piano, ou, por um grito que ecoa em um vazio multifacetado de sujeitos e barulho infernal no urbano contemporâneo, a Estação da Luz nos transporta para um mundo outro, quase sempre, como se estivéssemos em um filme de ficção.

Do lado de fora da Estação, pulsa aquilo que o poder das oficialidades não alcança: o tráfico, a prostituição, a violência, o chamado mundo das periferias da sociedade contemporânea. As ruas centrais guardam nichos de moradores de rua, dependentes químicos, pequenos batedores de carteira e traficantes de pedra. Há certa força na forma despedaçada como eles desfilam sua privacidade em público, abrindo a ferida de um Estado que não alcança todos, tampouco assiste igualmente a todos. Mulheres e homens perambulam; alguns, com batom excessivamente vermelho, buscam os que ali carregam suas dores cotidianas e prometem alento anestésico de uns poucos minutos por uma língua inatingível e de madeira como nos ensina Gadet e Pêcheux (1981), pois:

La question de la langue est donc bien une question d'Etat, avec une politique d'envahissement, d'absorption, d'anulation des différences, qui suppose avant tout que celles-ci soient reconnues : l'altérité constitue dans la société bourgeoise un état de nature quasi biologique, à transformer politiquement (GADET; PECHEUX, 1981, p. 36).

E esse espaço abre, no centro denominado "antigo" ou "deteriorado" da cidade, um lugar para monumentalizar a língua portuguesa, não 
todos os modos de inscrevê-la, mas um deles. Lugar esse tão propalado, referenciado mesmo, apontando, com novas políticas de patrimonialização, o que pela língua nos leva à criação do Museu da Língua Portuguesa (MLP), um lugar de todos e de ninguém pela língua que nos une e nos afasta.

\section{O museu...}

A palavra patrimônio, querida ao velho coração da França balzaquiana

A língua na e guardadora de tudo, servindo de política de arquivo ao mundo ocieconomia da luz dental, arremata-nos como algo sólido, capitalizável e estético, ao passo que para nós, brasileiros, o patrimônio ainda é algo vazio de concretude, talvez apenas o reflexo do interesse material possa contrabalançar o impulso a cumprir o gesto instintivo do homem contemporâneo: o de jogar fora (CALVINO, 2010), “[...] porque nossos olhos e nossas mentes como espaço de reflexão sobre o que somos estão habituados a escolher e a catalogar apenas aquilo que entra nas classificações assentadas. Talvez um Novo Mundo se abra aos nossos olhos todos os dias e não o vejamos" (p. 18). o patrimônio nos fica como algo que se "assemelha cada vez mais ao que nos sentimos diante do espelho: um espelho dotado do poder de revelar-nos alguma coisa do passado e do futuro" (p. 24). Uma espécie de inflação patrimonial, nas palavras de Nathalie Heinich (2009). Mas, com a emancipação social e, ao mesmo tempo, estética do mundo contemporâneo, aproximamo-nos de novas experiências de vida e de individualidade que colocam em cheque o que estava posto enquanto forma de agir tradicional. A partir do desmantelamento da velha divisão do visível, do pensável e do factível, “o que há hoje são simplesmente cenas de dissenso, capazes de sobrevir em qualquer lugar, a qualquer momento" (RANCIÈRE, 2012, p. 48).

Portanto, esse lugar, a Luz - e essa denominação/designação luz não é pouca - serve, também, para pensarmos o dito Museu. Museu instalado em parte do complexo dessa estação. Portanto, a língua parece estacionar ali com sua estrutura andarilha de vagão, de trilho, de trem, mas, sobretudo, pelo seu trajeto de imprevistos. A pedra no caminho, o descarilhamento ao carregar a equivocidade e o incompleto de si, na diferença, pela indiferença de todos que ali transitam. Um paralelo inicial seria dizer que a língua, como os trens e as linhas férreas, funciona, mais ainda, pelos trajetos que não pode percorrer, pelo que não funda como caminho trilhado, por um aqui que ainda está por deslocar, por um lá ainda não alcançado. Ao escolher um roteiro, abandona outros: a língua na diferença pura, no que não pode ser em sendo, a língua que ao 


\section{Lucília M. S.} Romão

Amanda E. Scherer

mesmo tempo nos une e nos afasta, a língua do museu da língua tão distante e tão próxima de todos nós; há, portanto, “uma política da estética no sentido de que novas formas de circulação da palavra, de exposição do visível e de produção dos afetos determinam capacidades novas, em ruptura com a antiga configuração do possível" (RANCIÈRE, 2012, p. 63).

Temos ali, naquela Estação da Luz, uma língua como na metáfora de A maleta do meu pai na obra de Orhan Pamuk (2007). Aquela maleta guardada depois de tanto tempo que, chegada a hora de abrir, não é nada mais do que uma poeira na e da memória, nas histórias que ficaram por ali na periferia de tudo e de todos. A língua das metáforas impossíveis, dos grunhidos de não ler, dos indecifráveis enigmas da loucura, que pedem uma luta também por ela. O que vemos nesse lugar é a economia da língua: as trocas e os modos como a língua se modifica a cada ciclo produtivo, a cada investimento de desejo do sujeito; uma economia em que a singularidade comparece, ainda que aparentemente sabotada pela oficialidade de ser apenas uma. Pois sabemos, no dizer da poeta polonesa Szymborska (2012, p. 77), que:

Somos filhos de uma época/e a época é política.

Todas as tuas, nossas, vossas coisas/diurnas e noturnas, /são coisas políticas. Querendo ou não querendo,/teus genes têm passado político,/tua pele, um matiz político,/teus olhos, um aspecto político.

O que você diz tem ressonância,/o que silencia tem um eco/ de um jeito ou de outro político.

Até caminhando e cantando a canção/você dá passos políticos/sobre solo político.

E a língua, ali, também é um espaço estratégico a ser povoado, um espaço político, demarcado e controlado, porque a língua igualmente acolhe nela o que se pode dizer das perdas, dos restos, dos inomináveis mais humanos; ela recebe, abre-se em pernas de amar e caminhar e sempre no trânsito das estações, porque ali há sempre um grito imprevisto, uma sirene, uma canção entoada por um delirante em uma língua de não compreender, de pura filigrana do incompreensível. E isso ocorre porque existe sujeito, sujeito que a toma como sua e vai gastando-a no cotidiano, lascando pedaços de sua estrutura-trilho, viajando pela fala, pela falta e pelo equívoco. E, como sabemos, considerar esse movimento nos remete ao conceito de sujeito, pedra do anel da teoria de Michel Pêcheux (1975). Sujeito que toma a língua como sua em uma relação de afetação pela his- 
tória, visto que está implicado em um ponto da trama social e fala a partir de uma posição em que identificações se inscrevem:

\begin{abstract}
[...] todo sujeito-falante 'seleciona' no interior da formação discursiva que o domina, isto é, no sistema de enunciados, formas e sequências que nela se encontram em relação de paráfrase - um enunciado, forma ou sequência, e não um outro, que, no entanto, está no campo daquilo que poderia reformulá-lo na formação discursiva considerada (PÊCHEUX, 1988 [1975], p.173).
\end{abstract}

Nesses termos, o sujeito toma a língua, posto que este foi tomado por ela antes mesmo de tomar a palavra, implicado por redes de memória que lhe constituíram e enovelado por uma trama de significantes que lhe foram conferidos desde sempre. $O$ que estamos propondo aqui é tomar a língua do Museu em uma reflexão que a leve em conta não como objeto estático a ser museificado, tampouco como patrimônio que deva ser contabilizado em uma cronologia linear a partir de empréstimos linguísticos ou de usos sociais empreendidos. Entendemos que os sujeitos e os discursos sobre língua(s) são lacunares, intervalados e instalam um jogo de dizer que também inclui o calar, ou seja, fazem falar um campo de poder/saber dizer sobre língua.

Pêcheux (1975) propõe que se leve em conta a sutileza e a singularidade dos movimentos do sujeito, isto é, de onde ele toma a palavra transformando-a no correr de seus trilhos discursivos, criando um trajeto definido por esquecimentos dados pela interpelação ideológica. Assim, a língua dos que dormem nas ruas do centro antigo da capital de São Paulo é em cada posição em que se marcam espaços de inscrição urbana de heterogeneidade e dispersão. Isso porque os sentidos de/sobre língua estão em jogo na posição-sujeito de um morador de rua de modo diferente daquele com que um sujeito-policial o faz, ao patrulhar a segurança do patrimônio ali mesmo. Já a língua dos delirantes é uma, outra ainda a dos aflitos que correm atrasados para tomar o último trem; e quiçá podem ser tantas quantas permitem a(à) língua (ser) denominada portuguesa.

São os movimentos de giros constantes no trilho da estrutura que permitem a atualização e o acontecimento: foi Pêcheux (1983) quem nos orientou a pensar assim. Algo nos une a salvo em uma única língua - portuguesa, que por sinal é marca de nossa colonização linguística, nome próprio de uma tomada a ferro e cruz de um território com donos -; no entanto,
A língua na economia da luz como espaço de reflexão sobre o

que somos 
Lucília M. S. Romão

Amanda E. Scherer

algo nos separa sempre nos modos como tal língua é colocada em discurso a partir da singularidade de quem fala. Ao apresentar a noção de acontecimento nos termos de que "todo discurso é o índice potencial de uma agitação das filiações sócio-históricas de identificação, na medida em que ele constitui ao mesmo tempo um efeito dessas filiações e um trabalho [...] de deslocamento no seu espaço", Pêcheux (1983, p. 56) toma a língua em seus processos de desestruturação e reestruturação. Portanto, falar de sujeito e língua é, assim, marcar redes e trajetos sempre deslocantes, correndo e escapando a trilhos e vagões.

Tal traço particular e estrutural permite que a língua conserve-se pulsante, dançarina e acrobata de ordenamentos sempre outros; ou seja, língua que é constantemente acontecimento em termos do imprevisível. Porque sujeito existe, língua assim se configura e dá brechas ao equívoco e ao impreciso. Porque tudo não se diz, língua falta e "muita coisa importante não tem nome", como diz Rosa. Isso está posto em relação à estrutura que apontamos vigorar e circular na língua museificada, que orienta certos gestos de leitura sobre ela e que fixa um trilho e outro, instalando efeitos de didatização até gramatiqueira no acervo permanente do Museu. Todavia, há sempre a promessa do acontecimento na língua, e o literário com as exposições temporárias do Museu o fazem falar.

Nesses termos, colocamos a tensão permanente entre a presença/ausência de língua, entre o saber formal da língua e o acontecimento nas suas tramas, entre o dentro e fora do Museu como indicadores de contradição e de jogo entre posições diferentes de sujeitos envolvidos por uma mesma língua e distanciados nela mesma. É essa a língua que nos chama e nos falta ao pensar o Museu da Língua Portuguesa, isto é, o quanto de língua escapa ao que ficou ali documentado como oficial e legitimado por uma casa de memória como um museu... A língua das oficialidades está dada pelo institucional, mas o sujeito fala dela, falha com ela, falta nela... E isso marca algo inapreensível no funcionamento do que estamos tateando, algo que os poetas marcam tão bem em inúmeras ocorrências de seu fazer: "eu adivinho coisas que não têm nome e que talvez nunca terão", só para lembrar Clarice Lispector.

\section{A língua...}

O que vemos é que o de fora tem força e que nos coloca em choque e xeque em relação à língua do museu, pois faz da língua uma estação própria, sem parada, sem outra luz que não seja aquela em que o sujeito possa morar e 
desembarcar. A língua ali é transformar em língua esse olhar para dentro, a língua ali é estudar o mundo para o qual o passante se transporta quando se recolhe em si mesmo. Como na língua que se atravessa, aquela de Lenora de Barros, o Museu faz-nos passear por "varetas e teclas", como se pudéssemos fecundar a linguagem, pois, ao procurarmo-nos por ela, o que encontramos são meramente alfabetos para poder construir o que somos através de uma espécie de poematecituras de vidas possíveis, como na construção plástica da artista/linguista em sua criação de 2006, intitulada de No país da língua grande, dai carne a quem quer carne:

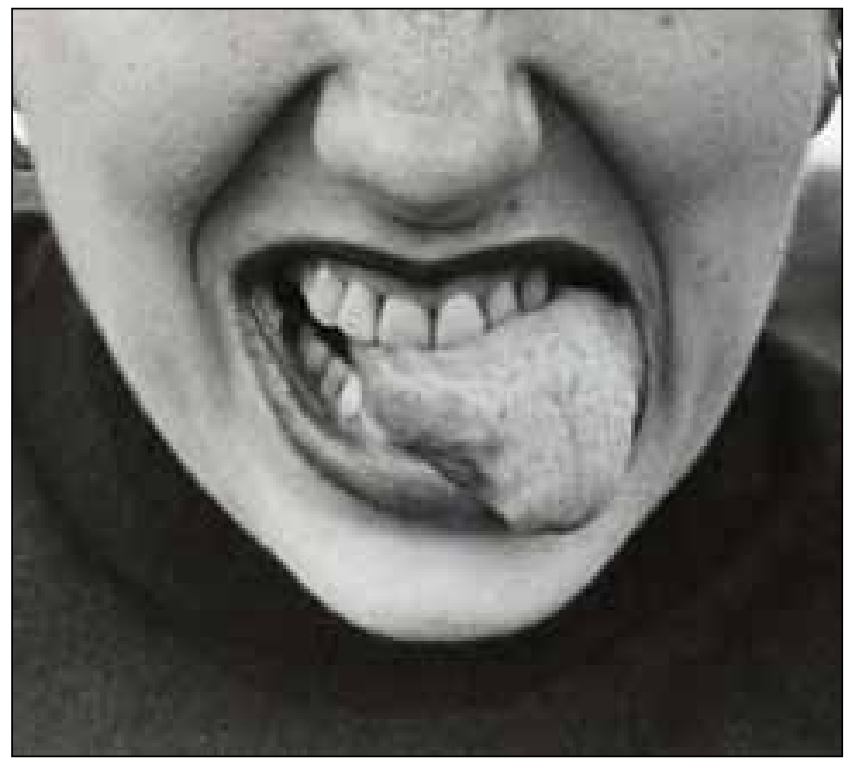

\section{A língua na economia da luz como espaço de reflexão sobre o \\ que somos}

Fotografia 1 - No país da língua grande/dai carne a quem quer carne - Autoria: Lenora de Barros (2011, p. 53)

Dessa forma, segundo a artista/linguista, a palavra se eterniza, marcando uma presença física como forma óbvia do dizer que se assimila ao que vivemos na Luz/luz. Mordendo a língua, mordendo nós mesmos, vamos nos identificando com o real da língua e da história se fazendo pelo simbólico, isso de que Clarice nos deu pistas anteriormente. Algo inatingível se constituindo em um todo que somos enquanto brasileiros no Museu da Língua Portuguesa, enquanto sujeitos à língua que falamos com um nome tão transposto do além-mar, enquanto falantes que sempre não conseguem dizer, restando-nos em uma fronteira com o indizí- 
vel: a língua que é carne da palavra em nós, que encarnada é margem de mordida, que no corpo produz ressonâncias de impossível dizer como no momento em que mordemos a língua sem querer e sem saber exatamente como foi. Isso nos coloca com uma margem terceira, que Caetano tão bem expressou ao tocar a (sua) terceira margem de Rosa.

Lucília M. S. Romão

Amanda E. Scherer 346

$$
\begin{gathered}
\text { Margem da palavra } \\
\text { Entre as escuras duas } \\
\text { Margens da palavra } \\
\text { Clareira, luz madura } \\
\text { Rosa da palavra } \\
\text { Puro silêncio, nosso pai }
\end{gathered}
$$

E como muito bem nos mostra Lenora de Barros, buscando abraçar o espaço com a palavra, em uma espécie de escrever/ler para dentro de nós mesmos, misturamos línguas, sexos, sociabilidades primeiras do contemporâneo da linguagem. Os corpos somem e reaparecem na Estação da Luz, somem pela palavra que reina sozinha neste espaço sem luz, especialmente quando a rua é morada e as violências de toda sorte são cotidianas. A língua dá-se a ver com todos os seus sufixos, prefixos, infixos. A língua materializando o lugar daquele que está fora e, ao mesmo tempo, está dentro, pois presa a ela, o sujeito não consegue se ver por inteiro, apenas lambe as suas bordas naquilo que ela tem de mais opaco e mais duro da realidade perene em um regime de historicidade (HARTOG, 2003) próprio ao presente do tempo e de histórias.

Língua que fecunda e funda a diferença. Língua máquina, língua liquefeita, língua que volta a se emoldurar em língua de madeira. Mas, para nós, o problema não é como descrevê-la, mas de se perguntar:

\footnotetext{
[...] qu'est-ce qui se passe lorsque la langue devient 'de bois' autrement dit lorsqu'elle se lignifie? En quoi consiste cette lignification de la langue analogue à une pétrification? Avec cette exigence corrélative: comment contrecarrer ce processus, ou lui résister lorsqu'il est déjà engagé? (DEWITTE, 2010, p. 48).
}

O que acontece com a língua em estar ali só por estar no Museu, mas estando não podendo mais fugir ao que significa e ao que cria fronteira entre um eu e um tu? A quem se dirige esse tu? Quem interpela esse 
eu? Será que ele é ponto de partida que faz falta e que falha na Estação da Luz e que ali está apenas para situar um tempo que já foi e que se desenhou como aquele da partida? Ou será que a língua de nos dizer como sujeito é sempre um engodo, e por isso temos que tomar a palavra de novo e mais um pouco e outra vez? Que língua mordemos diariamente para continuarmos vivos? Até onde temos nossa língua de morder, ou será ela que nos morde com a incompletude dela?

A língua na economia da luz como espaço de reflexão sobre o

que somos

Fotografia 2 - Língua vertebral - Autoria: Lenora de Barros (2011, p. 61)

Trazemos acima mais um trabalho de Lenora de Barros, denominado Língua vertebral, pois é bastante criativa a analogia língua com a coluna vertebral. Sim, ambas são da ordem de estrutura semelhante. Os ossos engatados uns aos outros, a sequência estrutural de amarração e uma articulação que precisamente institui uma peça atrás ou na frente de outra. Tal trama que garante a estrutura (e a ereção do corpo...) é composta por pequenos discos revestidos de cartilagem, de anéis macios, de espaços passíveis de alongamento para que as vértebras tenham maleabilidade e possam garantir o movimento.

A língua (a outra) sobre a língua da boca guarda algo dessa or- 


\section{Lucília M. S.} Romão

Amanda E. Scherer

dem... Primeiro, é de ouro tal estrutura que se deposita sobre a carne viva, estrutura inscrita desde a entrada (e desde a entrada do sujeito no simbólico), depositada até o final do órgão (e até que o sujeito não chegue ao final do seu dizer), posta para fora do corpo também. Posta para fora, já que o discurso é língua em circulação, instalado no jogo do social, na trama da história. A língua - da fotografia - é a orquestra da fala, o motor do dito e entra aqui como metáfora da língua - a nossa - com a qual (não) fal(h)amos. De sorte que estão em cena aqui a língua-órgão e a língua-palavra, entremeadas pela tessitura de um sujeito que faz com sua coluna os movimentos que consegue e pode, e aquele que está autorizado a inscrever a partir da posição que ocupa. A língua no corpo do discurso é aquela que Pêcheux (1983) aponta como estrutura sobre a qual a coluna de dizer do sujeito irá produzir movimentos de repetição ou acrobacias de deslocamento. A língua exposta, colocada à mostra, esticada a partir do ou(t)ro que guarda; é ela que nos permite movimentos de (des)encontro com o sujeito, com o outro e com o silêncio.

Para nós, o nó está no fato de que é pela língua que a relação eu e tu faz ecoar e ao mesmo tempo desviar os trilhos da estação para fazer sua próxima parada no Museu da Língua; ali, um/o desenho de um processo atado por sua própria estrutura tenta segurar o sujeito e suas significações. E recorrendo, novamente, à Lenora de Barros, como em SÓ POR ES-TAR (2009), um texto poético criado pela artista/linguista e que ela vai escrever na sola de seus pés, cujos passos revelam sílaba por sílaba: ES-TAR EM SI SÓ POR ES-TAR SAL-TI-TAN-DO SO-BRE AS SÍ-LA-BAS DO SI-LÊN-CIO. O Museu da Língua Portuguesa, então como as sílabas do silêncio na construção de uma brasilidade, saltita a todos que o visitam guiados por um tempo que podemos mexer como nos ponteiros de nossos velhos relógios, com aquela vontade de burlar o tempo, o tempo da língua, da língua do sujeito, da nossa língua, fazendo com o que o espaço da página em branco se transforme via performance, vídeos, fotografias e tantos outros mecanismos plásticos em uma espécie de antropofagia estética do que somos.

Essa instância de sílabas de silêncio é o que nos leva a pensar o quanto da língua fica fora do Museu, posto que não toca o impossível-dizer. Nos totens eletrônicos, nos painéis projetados com belas imagens e letras de música, nos espaços interativos do MLP e na forma como a cronologia da língua portuguesa está apresentada, reina uma tagarelice de sílabas de língua, onde apenas o dizer cabe e tem envergadura de 
possibilidade. Ali, diz-se, e muito. Estão em curso a palavra e a palavra. O silêncio e o impossível restam ao sujeito, como espaços não nomeados no âmbito institucional. E eles são na língua, e ele somos nós.

\section{Somos nós...}

A língua no Museu, para nós, ganha corpo no modo como se deve escrever, falar, poetar, legitimando o idioma pátrio. Oficializa e torna evidente, pelo efeito ideológico, o que é o português (e aqui vale a polissemia) e de que modo ele pode/deve ser catalogado (os totens e a cronologia explicativa fazem isso muito bem), dividido, tratado em períodos e empréstimos, explicitado e "plenamente" compreendido em seu funcionamento. O português, cuja narrativa o Museu da Língua Portuguesa oferece ao modo de um manual, anota o que precisa/deve e pode ser en-

A língua na economia da luz como espaço de reflexão sobre o que somos sinado, visto, transmitido como regra e o faz tensionado regionalismo, poesia, oralidade. Entre a raiz e a desinência, entre o trilho e a Estação, no intervalo entre duas palavras, a língua do Museu, a língua da nação. Língua partida sem chegada, puro trem em trânsito que tanto precisa ser domesticado na rota, oficializado nos horários de ir-e-vir. Língua do sujeito, mas sem que ele apareça nas instâncias do Museu; língua das sílabas de silêncio, mas sem que elas sejam ouvidas nos espaços construídos do Museu.

A língua portuguesa, sobremaneira, que não pode guardar, em nome, outra nacionalidade que não a do colonizador. Um MLP tem muito a nos dizer: o ponto que julgamos mais importante é o de pensar a língua na dobradiça entre o oficial e o considerado marginal, entre a trama gramatical e a forma como o sujeito é tomado por ela, desestabilizando sempre os nomes e as coisas. A língua se atravessa, então, pela luz na Estação da Luz, por um espectador emancipado nos termos de Rancière (2012, p. 63), para enunciar o paradoxo e, ao mesmo tempo, o heterogêneo da relação língua e política, "no sentido de que os atos de subjetivação política redefinem o que é visível, o que se pode dizer dele e que sujeitos são capazes de fazê-lo".

Essa língua em museu significa-se, então, na tensão entre o que está dentro e o que está fora do prédio da Estação, tensão entre o oficial e o vivido para além de qualquer tentativa de controle, tensão entre os que estão dentro da língua e os que falam marginalidades. Uma volta no entorno e veremos que, por ali, as línguas, também, pululam: imigrantes africanos travam a língua e inscrevem o diferente, um dizer 


\section{Lucília M. S.} Romão

Amanda E. Scherer

que vai ruidando outras acontecências. Migrantes desembarcados de regiões distantes anotam suas expressões e cantorias de outros cantos, outros nomes para a grande cidade onde se arriscam. Transeuntes em desvario cantam enigmáticas alínguas; são delirantes que nos dizem de uma língua outra, alíngua com a qual Pêcheux (1981) irá se ocupar em $A$ língua inatingível. Drogados inscrevem, no deslizamento de suas línguas, o que é difícil de entender em um mosaico aberto a céu do imaginário. As prostitutas falam a língua que só se diz ao pé do ouvido, uma outra ainda. Os meninos que foram alfabetizados na língua da rua continuam a repetir, tantas vezes da mesma forma, o que já ouviram. Outros tantos correm a dizer a língua de si mesmo no cotidiano, a língua em estado de domingo e não de dicionário, descomportada e descabelada, sem se olhar no espelho. A língua de todos os prazeres, de não saber dizer com palavras, de errar pelas ruas do Parque da Luz e de tracejar errâncias como próprio sujeito do entorno da Estação. Os trens, o Museu, a Pinacoteca, o parque, as ruas do comércio feminino, o Memorial da Resistência: nesse cenário, está posta a língua de despalavrar, de desentender, de desdizer... A língua de tropeçar e de rir, de guardar-se em espera de uma estação (utópica?) em que todos possam ter direitos, os mesmos, de fato... Essa língua não cabe em nenhum museu, essa língua somos nós mesmos na contravenção de nossa singularidade, na rebeldia dos nossos desdizeres a inventar uma língua que nos seja própria; a língua nossa de todo dia. Assim seja.

\section{Referências}

CALVINO, Italo. Coleção de areia. Tradução de Maurício Santana Dias. São Paulo: Companhia das Letras, 2010.

DE BARROS, Lenora. Relivro. Rio de Janeiro: Automática Oi Futuro, 2011.

DEWITTE, Jacques. La lignification de la langue. Hermès, n. 58 - Les Langues de Bois, Paris: CNRS Editions, 2010.

GADET, Françoise; PECHEUX, Michel. La langue introuvable. Paris: François Maspero, 1981. 
HARTOG, François. Régimes d'historicités: presentisme et expériences du temps. Paris: Editons du Seuil, 2003. Coll. La Librairie du XXI Siècles.

HEINICH, Nathalie. La fabrique du patrimoine. Paris: Editions de la Maison des Sciences de l'Homme, 2009.

LISPECTOR, Clarice. A paixão segundo G. H. Rio de Janeiro: Nova Fronteira, 1979.

PAMUK, Orhan. A maleta do meu pai. Tradução de Sérgio Flaksman. São Paulo: Companhia das Letras, 2007.

A língua na economia da luz como espaço de reflexão sobre o que somos

PECHÊUX, Michel [1983]. o discurso, estrutura ou acontecimento. Tradução de Eni P. Orlandi. Campinas: Pontes, 1997.

Semântica e discurso: uma crítica à afirmação do óbvio. Tradução de Eni P. Orlandi. Campinas: Editora da Unicamp, 1988.

RANCIÈRE, Jacques. 0 espectador emancipado. Tradução de Ivone C. Benedetti. São Paulo: Martins Fontes, 2012.

ROSA, Guimarães. Grande sertão: veredas. Edição comemorativa. Rio de Janeiro: Nova Fronteira, 2007.

SZYMBORSKA, Wilslawa. Poemas. Tradução de Regina Przybycien. São Paulo: Companhia das Letras, 2012.

VELOSO, Caetano. A terceira margem do rio. Disponível no endereço http://letras.mus.br/caetano-veloso/201521/. Acesso em: 21 ago. 2013. 